\title{
Landslide observation and volume estimation in central Georgia based on L-band InSAR
}

\author{
E. Nikolaeva ${ }^{1}$, T.R. Walter ${ }^{1}$, M. Shirzaei ${ }^{1, *}$, and J. Zschau ${ }^{1}$ \\ ${ }^{1}$ Department 2 - Physics of the Earth, Helmholtz Center Potsdam - GFZ German Research Center of Geosciences, \\ Potsdam, Germany \\ *now at: School of Earth and Space Exploration, Arizona State University, Tempe, AZ 85287-6004, USA
}

Correspondence to: E. Nikolaeva (elena.nikolaeva@gfz-potsdam.de)

Received: 21 August 2013 - Published in Nat. Hazards Earth Syst. Sci. Discuss.: 17 September 2013

Revised: 9 December 2013 - Accepted: 30 January 2014 - Published: 25 March 2014

\begin{abstract}
The republic of Georgia is a mountainous and tectonically active area that is vulnerable to landslides. Because landslides are one of the most devastating natural hazards, their detection and monitoring is of great importance. In this study we report on a previously unknown landslide in central Georgia near the town of Sachkhere. We used a set of Advanced Land Observation Satellite (ALOS) Phased Array type L-band Synthetic Aperture Radar (PALSAR) data to generate displacement maps using interferometric synthetic aperture radar (InSAR). We detected a sliding zone of dimensions $2 \mathrm{~km}$ north-south by $0.6 \mathrm{~km}$ east-west that threatens four villages. We estimated surface displacement of up to $\sim 30 \mathrm{~cm} / \mathrm{yr}$ over the sliding body in the satellite line-of-sight (LOS) direction, with the largest displacement occurring after a local tectonic earthquake. We mapped the morphology of the landslide mass by aerial photography and field surveying. We found a complex set of interacting processes, including surface fracturing, shear and normal faults at both the headwall and the sides of the landslide, local landslide velocity changes, earthquake-induced velocity peaks, and loss in toe support due to mining activity. Important implications that are applicable elsewhere can be drawn from this study of coupled processes.

We used inverse dislocation modelling to find a possible dislocation plane resembling the landslide basal décollement, and we used that plane to calculate the volume of the landslide. The results suggest a décollement at $\sim 120 \mathrm{~m}$ depth, dipping at $\sim 10^{\circ}$ sub-parallel to the surface, which is indicative of a translational-type landslide.
\end{abstract}

\section{Introduction}

\subsection{Landslides in Georgia}

Landslides and related hazards are widespread in Georgia (Nadim et al., 2006; Gracheva and Golyeva, 2010) and cause substantial damage annually (van Westen et al., 2012). The steep hillslopes, active geology and wet or even subtropical climatic conditions in Georgia (van Westen et al., 2012) are important factors that contribute to the high landslide susceptibility there. Over 5700 landslides have been identified, ranging from small-scale slumps to large-scale mass wasting of entire hillsides (van Westen et al., 2012). Approximately 700 of those landslides have been identified through year-long mapping and fieldwork activities. A recent landslide susceptibility analysis based on geology, slope classification and land cover mapping suggested that approximately $17 \%$ of Georgia is located in high-hazard zones, and another $38 \%$ is located in moderate-hazard zones (van Westen et al., 2012). Landslide concentration is especially high and covers all scales in Adzharia, a region in southwestern Georgia with a humid subtropical climate, with occurrence peaking in spring and during summer storms (Gracheva and Golyeva, 2010).

Together with the steep topography and wet climate, tectonics can be a significant trigger of landslides. The Ms 7.0 earthquake on 29 April 1991, for instance, triggered numerous landslides and caused a loss of infrastructure and life (Jibson et al., 1994). Some of these landslides were known to be active already, but moving slowly. For example, the slow-moving Chordi landslide accelerated and destroyed the village of Chordi shortly after the earthquake. This case 
highlights the importance of monitoring slow-moving landslides that may accelerate due to unpredictable external triggers. Slow-moving landslides in Georgia in particular can accelerate abruptly, especially if extrinsic factors act as triggers (Gracheva and Golyeva, 2010).

Although geologic mapping has been performed for some of these landslides, dynamic and kinematic analyses of them have received little scientific attention. As will be shown in this work, space-based data allow analysis of displacement rates and the identification of possible detachment planes of a landslide, which, together with aerial images, provide a detailed view of unstable masses and triggering factors ranging from tectonics to man-made activity.

\subsection{Landslide mechanisms}

The dynamics, i.e. the appearance and displacement pattern of a landslide, is primarily controlled by the geometry of the sliding planes (Cruden, 1986). These planes are made up of a combination of basal décollements and laterally delimiting fractures. The décollement is usually not directly visible and is also difficult to infer from remote sensing techniques. Therefore, little is known about the geometric complexities and dynamics of active décollement planes. The laterally delimiting fractures, in turn, are visible at the surface and commonly include a headwall fault, which is the surface expression of the main detachment, en echelon sets of strike-slip and normal faults on either side with opposite senses and a compressional zone in the landslide toe that forms thrust and fold belts. The geometry of these sliding planes affects the different types of movement. Movement of a landslide can be translational, rotational, or complex (Cruden and Varnes, 1996). Rotational landslides move generally downward and outward and are thought to be structurally confined by a curved basal detachment plane (Highland and Bobrowsky, 2008). Translational slides move hillslope-parallel and are structurally defined by a planar slope-parallel plane (Highland and Bobrowsky, 2008). Most landslides likely involve a combination of rotational and translational mechanisms. Because the network of these structures delimits the mass of a landslide, structural characterisation of a landslide is important for assessing the landslide volume.

Landslides exhibit a wide range in velocity, from extremely slow $\left(10 \mathrm{~mm}\right.$ year $\left.^{-1}\right)$ to extremely rapid landslides $(10 \mathrm{~m} / \mathrm{s})$ (Cruden and Varnes, 1996). This broad velocity range highlights a common problem in landslide monitoring: the ability to detect and explore several scales of displacement magnitude. This problem is described further in the following section.

\subsection{Landslide detection and displacement monitoring}

Most active landslides are studied using field-based morphological, structural and kinematic analyses. Ground-based techniques are not appropriate for detecting a landslide in a broad area because of the limited spatial resolution. Nonintrusive remote sensing techniques have therefore become widely used for the detection and mapping of the position, size and shape of landslides (Cardenal et al., 2001; Guzzetti et al., 2012) and potentially unstable slopes (Colesanti and Wasowski, 2006; Ouimet, 2010). Remote sensing techniques have specifically contributed to define states of activity, to monitor landslides, to improve hazard analysis and to allow implementation in early warning systems (Canuti et al., 2007). Remote sensing methods include aerial photographs, multispectral optical images (Qi et al., 2010), differential digital elevation models (DEMs) (Casson et al., 2005), interferometric analysis of radar images (Riedel and Walther, 2008) and lidar data (Schulz 2004; Jaboyedoff et al., 2010) and others.

The most commonly used method for landslide detection is the visual interpretation of optical images (Tofani et al., 2013). Change detection techniques (Nichol and Wong, 2005) and classification with semi-automated object-oriented methods (Martha et al., 2010) in optical imagery allow for landslide mapping. Together with detection, these methods allow monitoring and reconstruction of year-long time series. For instance, rapid and large morphometric changes can be quantified using change detection methods applied to highresolution optical data (Nichol and Wong, 2005). The combination of these methods is also used to improve landslide inventory maps (Guzzetti et al., 2012).

Interferometric synthetic aperture radar (InSAR) techniques allow mapping of ground movement that occurs between two acquisition times (Hanssen, 2001). InSAR techniques are increasing in popularity for landslide applications (Colesanti and Wasowski, 2006; Riedel and Walther, 2008; Tofani et al., 2013) as they are low-cost, almost globally applicable, high-resolution and independent of day or night. The traditional two pass differential InSAR method allows the detection and monitoring of slow (several $\mathrm{cm}$ per year) landslides, following the classifications of Cruden and Varnes (1996). Persistent scatterers SAR interferometry (PSInSAR) and Small BAseline Subset (SBAS) techniques allow analysis of the temporal and spatial evolution of extremely slow landslides (several mm per year) (Colesanti et al., 2003b; Hilley et al., 2004; Guzzetti et al., 2009). Combinations of different InSAR techniques are useful to detect and investigate different rates of landslides (García-Davalillo et al., 2013).

Each of these techniques has its advantages and disadvantages. Combining optical and radar techniques creates suitable conditions for the study of landslides (Strozzi et al., 2013). In this work, we exploit aerial optical, satellite 


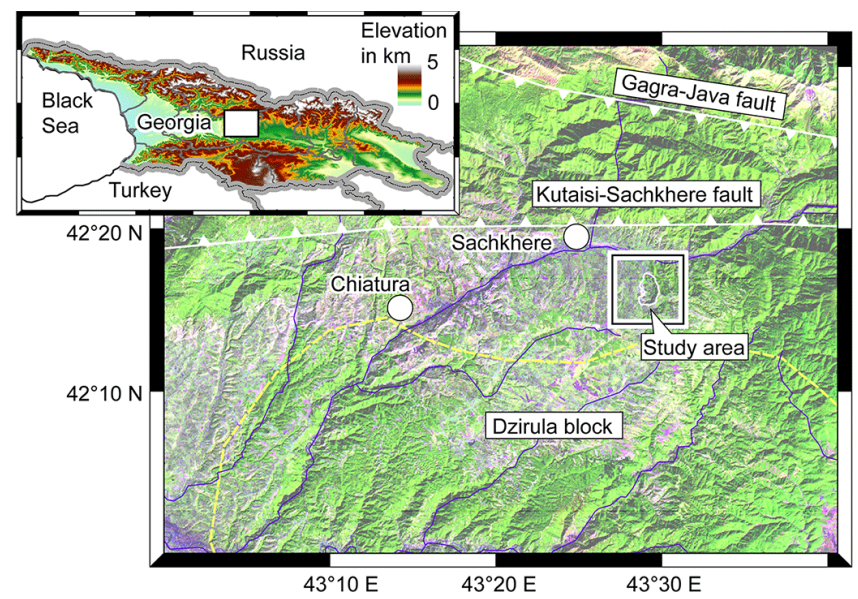

Fig. 1. Map of central Georgia showing land cover based on Landsat TM information. The combination of bands 5, 4 and 3, represented with red, blue and green, respectively, shows vegetation in bright green colours and soil in mauve colours. The violet curves close to Sachkhere and Chiatura show the main path of the Kvirila River. The location of the Itskisi landslide is near Sachkhere. Faults indicated by white symbols are thrust faults. The faults were defined by Gamkrelidze (1978).

spectral and, foremost, InSAR data to analyse the dynamics and changes of a landslide.

\section{Study area}

We concentrate our study on a site located in the central western part of Georgia $\left(42.30^{\circ} \mathrm{N}, 43.48^{\circ} \mathrm{E}\right)$ because of the known landslide potential, slope angle and field access there. We use a specific constellation to investigate the effect of extrinsic forcing (Fig. 1). Geologically, the region belongs to the Dzirula block, which is a topographic feature of the Chiatura formation (Gamkrelidze and Shengelia, 2007) (Fig. 1). The geologic Chiatura formation was created by sedimentary deposition, with a sequence of quartz-arkosic sandstones and sands underlying an ore horizon that is overlain by siliceous sedimentary rocks to the west and shales and shaly sandstones to the east (Edilashvili et al., 1974; Leonov, 1976).

The relief profile of the study area shows a gently sloping morphology. The height varies only from 500 to $850 \mathrm{~m}$; thus the slope is moderate, with slope angles less than $20^{\circ}$. A significant part of the lower landslide flank is subject to mining activity (Fig. 2), where quartz sand is excavated. The nearby Kutaisi-Sachkhere thrust fault, located just $\sim 5 \mathrm{~km}$ to the north of the landslide area (Gamkrelidze and Shengelia, 2007), is thought to be active (seismic catalogue of Georgia, http://seismo.ge) and thus has the potential to be an unpredictable landslide trigger (Fig. 1). Other faults at larger distances may also dynamically trigger the landslide, simi-
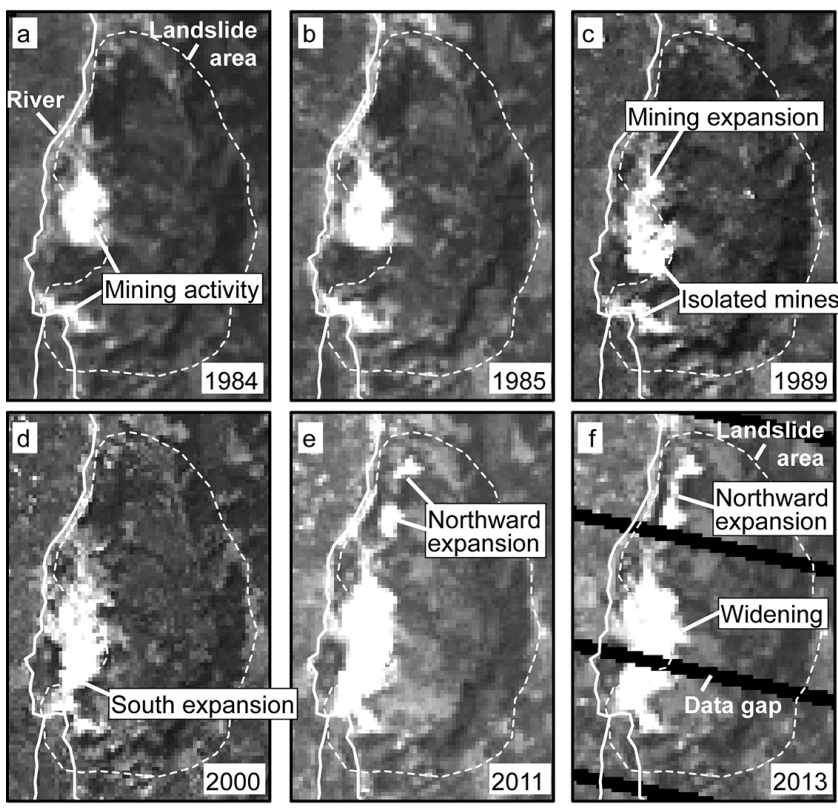

Fig. 2. Time series of Landsat images showing the development of the mining area. The spatial resolution of the images is $30 \mathrm{~m}$. These images emphasise the vegetation and the boundary between land and water. Bright colours indicate bare soil, which in this case is the mining area. Panels (d-f) show several expansions that have opened over the last 20 years.

lar to the 1991 Racha earthquake-triggered landslides at over $30 \mathrm{~km}$ distance (Jibson et al., 1991; Jibson et al., 1994).

\section{Data and methods}

\subsection{Data}

Data analysed comprise (a) satellite radar observations, (b) optical Landsat data and aerial photographs, (c) digital elevation data and (d) field inspection. The main focus of this work is on the satellite radar observations and interferometric processing.

To generate the InSAR maps, we considered 12 images of the Phased Array type L-band Synthetic Aperture Radar (PALSAR) acquisitions from the Advanced Land Observing Satellite (ALOS). In many other satellite radar data, the phase quality of the SAR signals degrades due to changes in the backscattering properties of the surfaces (e.g. vegetation), which is less critical in L-band sensors (Strozzi et al., 2005). The ALOS archives of our study area contain only data acquired in ascending orbits, track 582 and frame 840 , which means that the ground is observed by the satellite only from the west. The data set spans the period from July 2007 through June 2010. Five images are high-resolution singlepolarisation (fine mode single (FMS) polarisation) mode and 7 images are high spacing, dual-polarisation (fine beam double (FBD) polarisation) mode. The range resolution is $10 \mathrm{~m}$ 
for the FBS mode and $20 \mathrm{~m}$ for the FBD mode. The azimuth resolution is $5 \mathrm{~m}$ for both modes. To avoid decorrelation associated with snow cover, we excluded scenes acquired in winter periods. The periods between master and slave images range from 46 to 138 days. The distance between two satellite positions (orbits) characterised by a spatial baseline was at most $1885 \mathrm{~m}$, which is smaller than the critical spatial baseline for ALOS (Sandwell et al., 2008).

We also tested radar data available from other satellite missions, such as ERS1/ERS2 and Envisat (C-band), however, we found the interferograms to be of very low quality. We attribute this to the shorter wavelengths of these sensors compared to that of the ALOS L-band. The C-band has difficulty penetrating through vegetation; therefore, the signal may be decorrelated due to the vegetation (Wei and Sandwell 2010). The L-band penetrates the vegetation much better than the C-band does (Wei and Sandwell, 2010).

Landsat images from the Global Land Cover Facility (GLCF) catalogue were used to trace the development of the mining activity. We selected cloud-free images from the 30 -year catalogue. We used Landsat TM band 7, i.e. shortwave infrared $(2090-2350 \mathrm{~nm})$ for Landsat 4-5 (TM), as shown in Fig. 2a-c and e and Landsat 7 (ETM+), as shown in Fig. $2 \mathrm{~d}$ and $\mathrm{f}$, with $30 \mathrm{~m}$ resolution. The spectral reflectance of dry soil or sand increases with wavelength and peaks at wavelength 2000-2200 nm (Chudnovsky and BenDor 2008). Therefore, sand is highly visible in band 7. Band 7 is also sensitive to the moisture content of the soil and vegetation. Moreover, the area of interest was analysed using aerial photographs with pixel resolution $\sim 0.6 \mathrm{~m}$ that were recorded in 2007, at the beginning of our InSAR data set. We also studied geological (Edilashvili et al., 1974), land cover and topographic maps (scale $1: 5000,1972$ ).

An ASTER DEM (resolution $30 \mathrm{~m}$ ) was used for morphology analysis and InSAR processing. We also tested a Shuttle Radar Topography Mission (SRTM) DEM (resolution of 1 and 3 arc seconds), which did not change our results.

In August 2011, we visited the area of the Itskisi landslide. We validated the evidence for this landslide and mapped fractures related to the landslide in the terrain. We found newly formed cracks, some of them hidden by vegetation, mapped and measured them with handheld GPS units, and compared them to the InSAR and aerial photography database.

\subsection{InSAR}

The SAR interferometry (InSAR) method is the complex multiplication of two radar images of the same ground target (Hanssen, 2001). Each radar image contains amplitude and phase information. The interferogram is calculated by differencing the phase component of the two coregistered radar images. The InSAR was successfully used for landslide detection and monitoring (Colesanti et al., 2003a; Colesanti and Wasowski, 2006).
To start the interferometric analysis, we coregistered all SAR images to the image acquired at 4 September 2009. Thus, each pixel in all images corresponds to the same location on the ground. Raw images from the FBD mode $(14 \mathrm{MHz})$ were transformed to an FBS mode spacing $(28 \mathrm{MHz})$ using the ROI_PAC (Repeat Orbit Interferometry Package) software. Using DORIS (the Delft Object Oriented Interferometric Software) software (Kampes and Usai, 1999), we built interferograms that contain the phase information for each acquisition. The effect of topography was calculated and removed from each interferogram using the ASTER DEM and satellite ephemeris data (Hanssen, 2001). Results are based on the assumption that the ASTER DEM properly reflects the topography during differential InSAR measurements. We generated multi-look images from interferograms with a factor of 2 . The multi-looking is necessary to equalise resolution in the azimuthal and in range directions. Therefore, the pixel dimensions are approximately $9 \mathrm{~m}$ in the azimuthal direction and approximately $7.5 \mathrm{~m}$ in the range direction. The interferograms were low-pass filtered using adaptive spectral filtering (Principe et al., 2004). We choose only interferograms with coherence higher than 0.4 after filtering. The corresponding wrapped phase values were unwrapped using the branch-cut phase unwrapping algorithm (Goldstein and Werner, 1998) and SNAPHU, a statistical-cost network-flow algorithm (Chen and Zebker, 2002). To correct for the effect of orbital error, wavelet multiresolution analysis and robust regression were used (Shirzaei and Walter, 2011).

Some of the limitations of the InSAR method are related to geometric distortion, for instance as "layover" and "shadow" (Chen et al., 2011). In our case, however, the slope was mostly gentle, except for steep sections in the mining areas, where no observations were possible. Another limitation comes from the single viewing geometry and accordingly from the unidirectionality of the displacement vectors (Delacourt et al., 2007). Having only one viewing geometry prohibits the extraction of the 3-D displacement and may affect the interpretation of the deformation field.

\subsection{Photographic analysis}

The optical data of photographs were transferred to the WGS84 reference frame and analysed in a geographical information system (GIS) using ArcMap's editor functions. Only one aerial photography was available; thus the analysis concentrated on lineaments. This includes manual delineation and classification of lineaments, fractures, streams and ponds. We used the aerial photography in close comparison to the InSAR data. Specifically, fractures and morphologic expressions in the aerial photography were compared to changes in the displacement field derived from the InSAR data. This comparison allowed us to test which fractures were active and which were not. The contour map of the area was created from an ASTER DEM in ArcMap, using 3-D analyst 
From remote sensing to landslide volume estimation

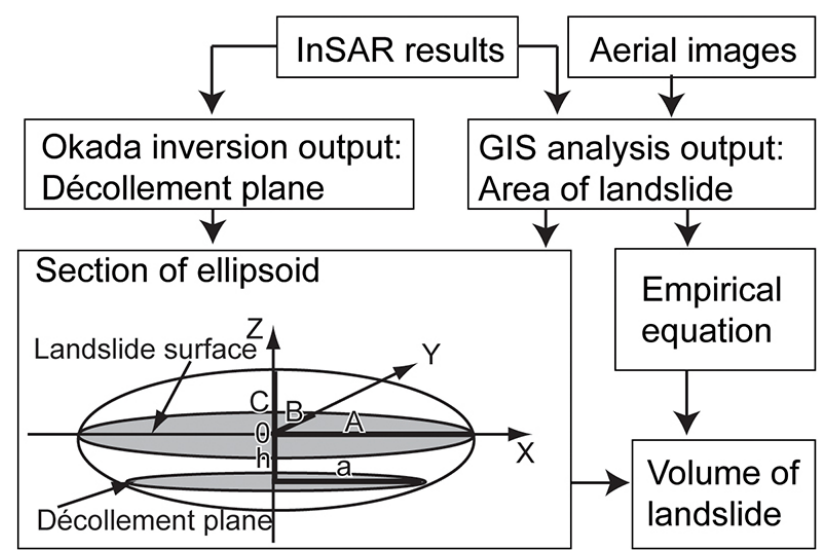

Fig. 3. A flow chart showing data and steps taken to estimate the landslide volume and a sketch of the geometric figure that we used for the volume calculation. "A" is the major axis of an ellipsoid in the $X$ direction, "B" is the major axis of an ellipsoid in the $Y$ direction and " $C$ " is the major axis of an ellipsoid in the $Z$ direction. $h$ is the distance between the plane of the landslide surface and the sliding plane. $a$ is the major axis in the $X$ direction of the sliding plane. The volume is calculated for the area enclosed between the plane of the landslide surface and the sliding plane.

tools. The area and perimeter of the landslide boundary were further analysed in ArcMap.

Photography taken by a geotagging camera allowed an even closer view of the selected structures and their comparison to InSAR data.

A larger view was possible due to Landsat imagery. After importing these image data to ArcGIS, we were able to visualise the growing extent of the mining activity and its effect on the displacement field.

\subsection{Modelling}

The sliding planes of a landslide play an important role in the activity of the landslide (Petley et al., 2002; Petley et al., 2005). Knowledge of the location, shape and the size of the sliding plane allows estimation of the landslide volume. To investigate the geometry of the sliding plane of the observed displacement, we applied inverse modelling techniques. Displacement maps produced from the InSAR data were used as input data. We followed previous kinematic landslide studies (Fruneau et al., 1996; Martel, 2004) where models were used to describe landslide processes. These elastic models consider a flat earth and a linear elastic rheology. In our model, the main rupture plane of the landslide was simulated by a planar dislocation plane (Okada, 1985). We herein considered this dislocation plane as a first-order approximation, because the model is simplified in a geometric and a physical sense. Geometrically, the models are simplified as they rely on the half space assumption and the rectangular dislocation plane, with an upper edge being parallel to the sur- face. Physically, the models are unrealistic as they rely on a linear elastic rheology and a dislocation along a plane. The dislocation plane we used has 8 unknowns: length, width, depth, two-dimensional position, dip and strike angles, and dip-slip dislocation components. We used the genetic algorithm to search the model and optimise the free parameters (Shirzaei and Walter, 2009), choosing a wide range of possible solutions for the model parameters as a starting point. The genetic algorithm defines a cost function and initialises the genetic algorithm's parameters.

We used this type of model because large landslides have structures similar to tectonic faults (Fleming and Johnson, 1989). Structures found inside a landslide (Fleming and Johnson, 1989) also motivated consideration of dislocation planes in translational landslide rupture models (Fruneau et al., 1996; Muller and Martel, 2000). We follow these previous works by assuming that our observed displacement fields from InSAR may be simulated by planar dislocations within an isotropic elastic half-space. All InSAR deformation measurements were inverted to test the stability of the décollement plane. Only model parameters that emerged when the genetic algorithm had stabilised, which means that the parameters had not changed for several iterations, were considered.

\subsection{Estimation of landslide volume}

A common way to calculate the rotational landslide volume is to assume that the soil mass has the shape of an ellipsoid (Cruden and Varnes, 1996; Marchesini et al., 2008). We expand on this concept by considering a more complex and realistic landslide geometry: one containing both rotational and translational components. A translational component is considered by an ellipsoid segment constrained by two parallel planes (Fig. 3). The lower plane is the décollement as inverted from our InSAR data, and the upper plane reflects the surface expression of the landslide (Fig. 3). There are two semi-major axes, $A$ and $B$. Consider the ellipsoid segment with décollement plane $z=h$, where $h$ is the depth of sliding plane. This plane is parallel to the surface plane $(X Y)$ located at depth $h$. The third vertical semi-major axis $C$ can be calculated as follows:

$a=A \times \sqrt{\left(1-(h / \mathrm{C})^{2}\right)}$,

where $a$ is the axis of the ellipse formed by a section plane $z=h$. It follows from the standard ellipsoid equation for the coordinates of point $(a, 0,-h)$. Then, we are able to calculate the volume of the ellipsoid segment, which is constrained by the two dipping planes: 

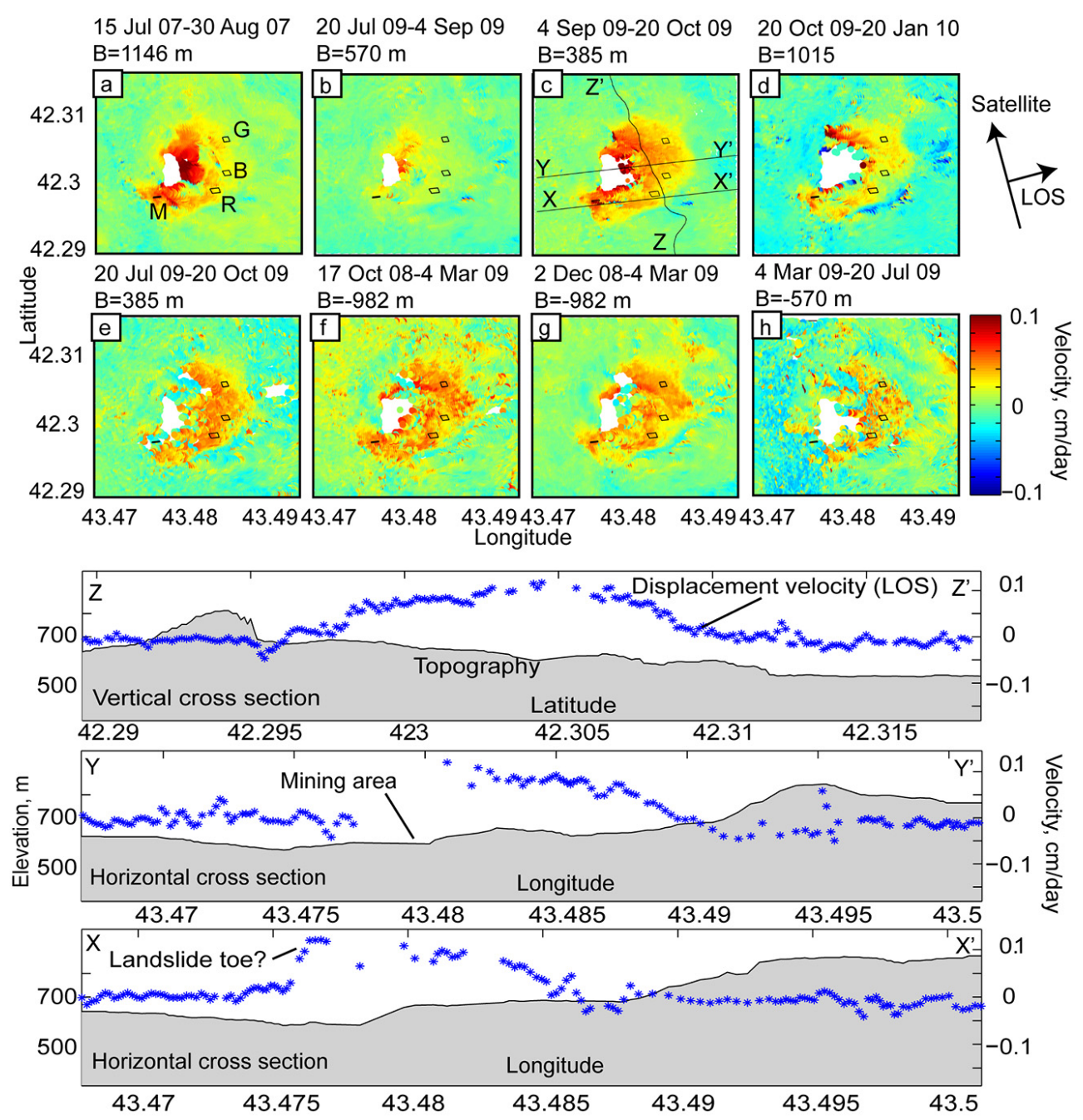

Fig. 4. Velocity $\left(\mathrm{cm} \mathrm{day}^{-1}\right)$ in the line-of-sight (LOS) direction from InSAR data. Given above each image are the two acquisition dates and the spatial baselines (B). Interferograms that are temporally or spatially decorrelated are not shown. Black lines show the profiles on plot (c), for which the topography and displacement velocities are shown below $\left(Z-Z^{\prime}, Y-Y^{\prime}, X-X^{\prime}\right)$. Polygons are marked with the letters "G", "B", "R" and "M" (panel a) and present areas where average velocities were calculated for Fig. 9.

$V=\int_{0}^{h} \pi \times A \times B \times\left(1-\frac{z^{2}}{\mathrm{C}^{2}}\right) \mathrm{d} z=\pi \times A \times$

$B \times\left(h-\frac{h^{3}}{3 \times C^{2}}\right)$.

An alternative way to evaluate the volume of a translational or rotational landslide is based on the landslide erosion rate (Hovius et al., 1997; Malamud et al., 2004; Larsen et al., 2010), where the predicted volume $V$ of a landslide of area $S$ can be approximated by the following empirical relation:

$V=0.05 \times S^{1.3}$.

The parameter 0.05 was determined empirically for soil landslides (Larsen et al., 2010). An exponent in the range of 1.1-1.3 characterises a soil landslide (Edilashvili et al., 1974), similar to our case in Georgia.

The flow chart (Fig. 3) shows the steps that allow evaluating landslide volumes using the above-described methods.

\section{Results}

\subsection{InSAR deformation field}

Figure 4 shows the unwrapped and geocoded versions of the InSAR data set. The warm colours (positive values) indicate motion towards the satellite, while cold colours (negative values) indicate motion away from the satellite (Fig. 4).

We found the surface pattern of the deformation area to be roughly kidney-shaped, where the major axis is approximately north-south parallel to the slope. The landslide is 

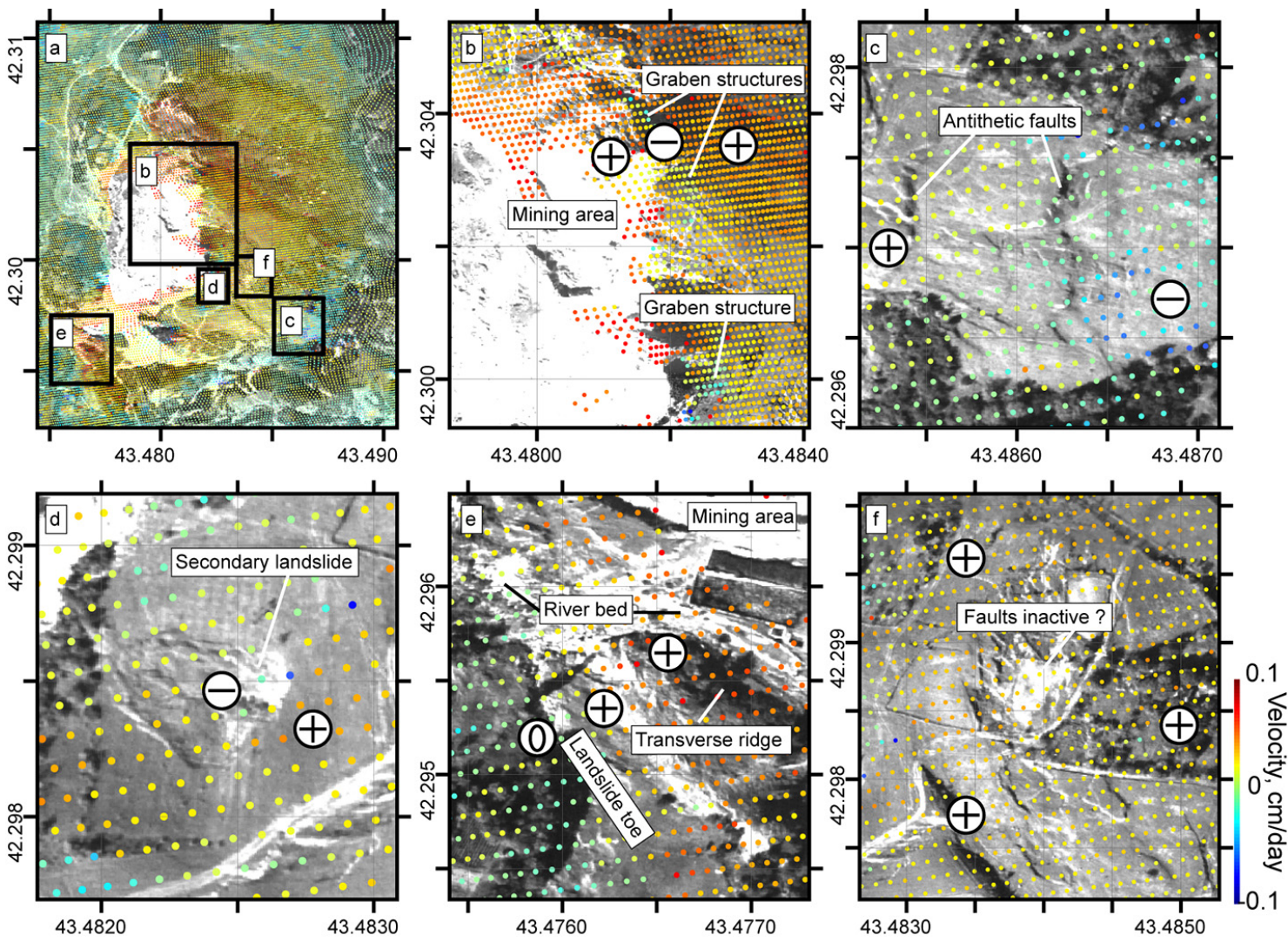

Fig. 5. (a) Aerial photography covered by a displacement map derived from InSAR. (b-f) details of the black boxes in (a), allowing a comparison between the displacement map and the morphology. Red pixels show movement towards the satellite. See text for discussion.

hence approximately $2 \mathrm{~km}$ long (north-south) and $0.6 \mathrm{~km}$ wide (east-west). A similar pattern emerges from all interferograms, which confirms the displacement occurrence. However, the amplitude of the displacement varies, occasionally even if the same duration is bracketed by the data (Fig. $4 \mathrm{a}-$ c). This observation complicates the study because the landslide process is found to be highly non-linear. The displacement velocity sharply increases in the interferogram from 4 September 2009 to 20 October 2009 and extends to almost the entire kidney-shaped landslide surface. The maximum difference between interferograms from 4 September 2009 to 20 October 2009 and 20 July 2009-4 September 2009 reaches $5 \mathrm{~cm}$. We will provide more information about the possible reasons for different amplitudes in the discussion section.

Three profiles taken from one of the InSAR images (Fig. 4, profiles $Z-Z^{\prime}, Y-Y^{\prime}, X-X^{\prime}$ ) clearly indicate that no displacement was observed outside the landslide. The bulk of the landslide moves at similar rates, except that sharp gradients can be observed in the toe region. The gaps (Fig. 4, profiles $Y-Y^{\prime}$ ) indicate areas of mining activity, where no data are presented due to mining activity, steep topography or erosion.

\subsection{Comparison of InSAR to optical images}

The surface of the landslide is hummocky and fissured. We found several local protrusions and depressions on the landslide body, which were also clear from the profile (Fig. 4, profiles $\left.Z-Z^{\prime}, Y-Y^{\prime}, X-X^{\prime}\right)$. Figure $4 c$ presents locations of profiles (Fig. 4, profiles Z-Z', Y-Y', X-X').

We tested for correlation between the InSAR results and aerial photography (Fig. 5). In most cases, the displacement signals show a strong gradient within the activity zones of the landslide (Fig. 5b-e). Figure 5b shows active graben structures close to the areas of mining activity. Accordingly, these places show displacement gradients. Figure $5 \mathrm{c}$ demonstrates correlation between antithetic faults and the displacement map, best visible by the blue pixels on east side of fault. Figure 5d presents a secondary landslide where the scarp area has a negative displacement and the toe has a positive displacement compared to the InSAR results. The geomorphology is complex in Fig. 5e: the river path and the shape of topographic isolines suggest that the area was not part of the landslide. However, the displacement signal is similar to the signal on the landslide (Fig. 5e). This observation may suggest that the area was in fact part of the landslide. The gradient visible in the InSAR data correlates with transverse 

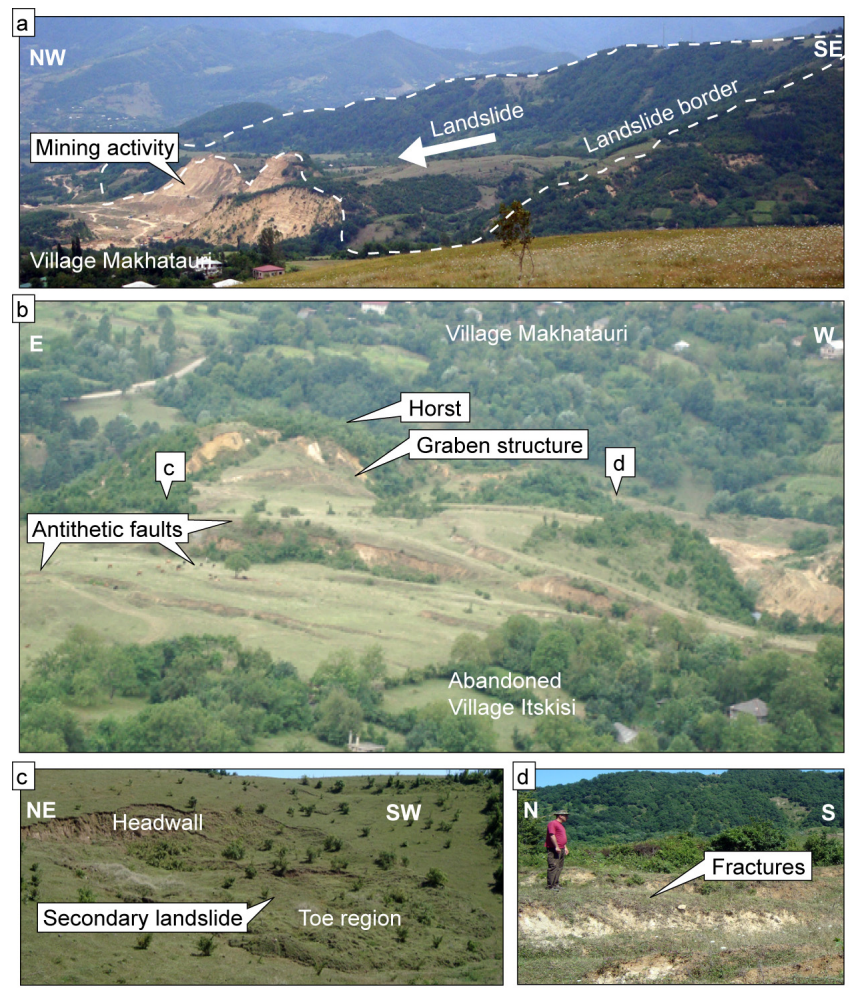

Fig. 6. View of the landslide from the northeast (a) and from the back of the landslide, east-west (b). There are slopes cut by mining activity in image (a). The white arrow shows the direction of landslide movement. The view of the landslide from the back (b) shows landslide activity structures that are present in the aerial photograph correlated with the InSAR signal in Fig. 5. (c) and (d) show secondary landslides and fractures, respectively. Their positions are shown in image (b).

ridges, possibly associated with the landslide toe. Figure $5 f$ presents an area where fault structures were observed in the field. However, the InSAR result does not show a significant displacement gradient, possibly indicating that the faults had not been active during the InSAR survey. The interferograms suggest that these and some of the fault areas are stable (Fig. 5a and f). It is likely that these landslide structures have either very low or no activity, or that any activity is masked by the high density of vegetation. These landslide structures are shown in both Fig. 5 and the survey photographs (Fig. 6).

Because the InSAR data were available only in ascending orbits, a reconstruction of the absolute horizontal and vertical components of the displacement was not possible. We assume, however, that most of the motion is westward because the morphology displays a slope orientation to the west (Fig. 6a). At localised regions, significant ground movement is detected at sites with slopes facing east, thus in the opposite direction. The observation that the movement is affecting both westward- and eastward-facing slopes may lead us to speculate that the type of movement is relatively deep seated and involves both synthetic and antithetic faults (Fig. 6b) to

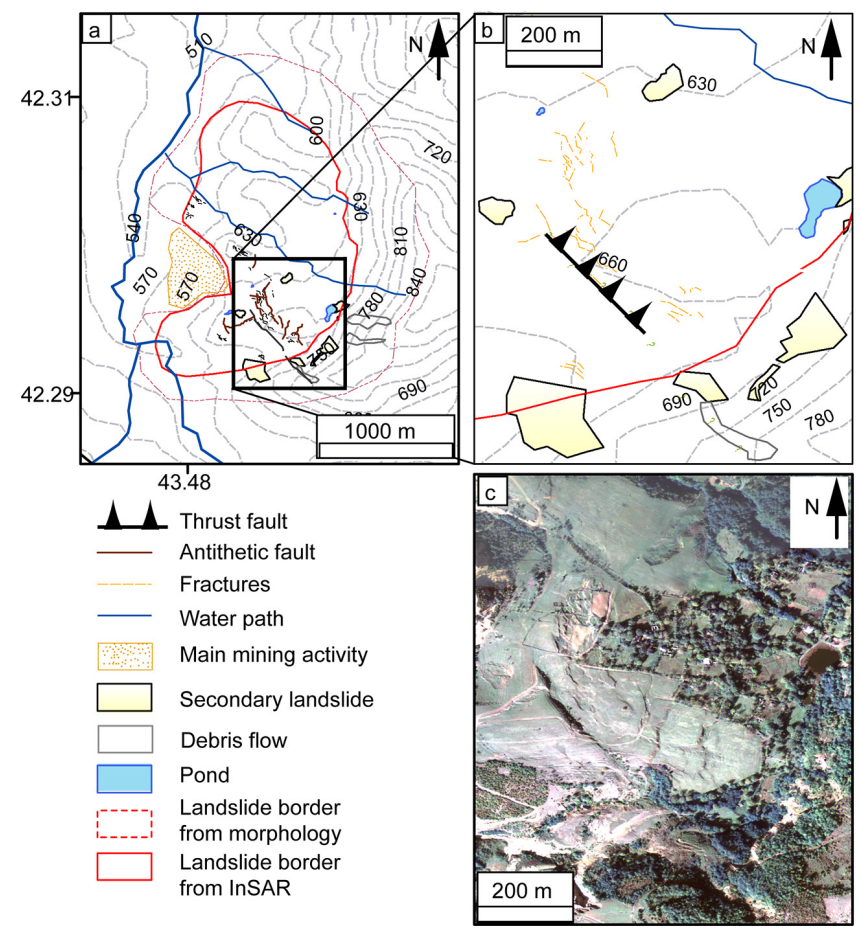

Fig. 7. Simplified structural map of the Itskisi landslide. Contour lines are based on SRTM DEM and have 30-metre intervals. The features mapped are presented in the legend. The possible body of the landslide is within the red line (a). The red dashed line shows the landslide boundary detected from the morphology. (b) is a detail of the black box in (a). Aerial photograph shows the fissured, hilly surface of the landslide (c). Structures are well aligned with the orientation of the Okada plane, as obtained from modelling of the landslide process (Fig. 8, Table 1, strike parameters).

form horst and graben structures. In other words, local morphologic features (Fig. 6c and d) and slopes have only minor influence on the moving mass, which is controlled instead by the large-scale topography and a deep-seated décollement.

Due to the slow rate of the landslide, the surface activity of the sliding area is not clear in optical Landsat satellite imagery (Fig. 2). Investigation of high-resolution aerial photographs, however, reveals further structural features such as folds, steps, lineaments, faults, outcrop sites and ponds (Fig. 7). We used these structural features to identify the type and complexity of movement for this landslide area.

We created a sketch of the landslide in GIS, using aerial and InSAR results as well as field observations (Fig. 7). We identified partly water-filled ponds in the transition zone of the centre to the upper part of the landslide (Fig. 7). Although the ponds and boggy areas are morphologically well explained, they were not present on the 1972 topographic map, implying that they developed more recently. Furthermore, some houses were built in locations where ponds are located today, for instance, close to the eastern slope (latitude $42.2975^{\circ} \mathrm{N}$, longitude $43.488^{\circ} \mathrm{E}$ ). In the field, we identified 
Table 1. Output parameters from inversion model for different interferograms (Fig. 8a-c).

\begin{tabular}{llllllll}
\hline Case & $\begin{array}{l}\text { Temporal } \\
\text { baselines, days }\end{array}$ & $\begin{array}{l}\text { Length, } \\
\mathrm{km}\end{array}$ & $\begin{array}{l}\text { Width, } \\
\mathrm{km}\end{array}$ & $\begin{array}{l}\text { Depth, } \\
\mathrm{km}\end{array}$ & Dip & Strike & $\begin{array}{l}\text { Dip-slip } \\
\mathrm{m}\end{array}$ \\
\hline $\mathrm{a}$ & 46 & 1.45 & 0.8 & 0.19 & $-9^{\circ}$ & -36 & -0.134 \\
$\mathrm{~b}$ & 46 & 1.3 & 0.6 & 0.12 & $-8.2^{\circ}$ & -40 & -0.17 \\
$\mathrm{c}$ & 92 & 1.37 & 0.67 & 0.14 & $-7.4^{\circ}$ & -39 & -0.12 \\
\hline
\end{tabular}

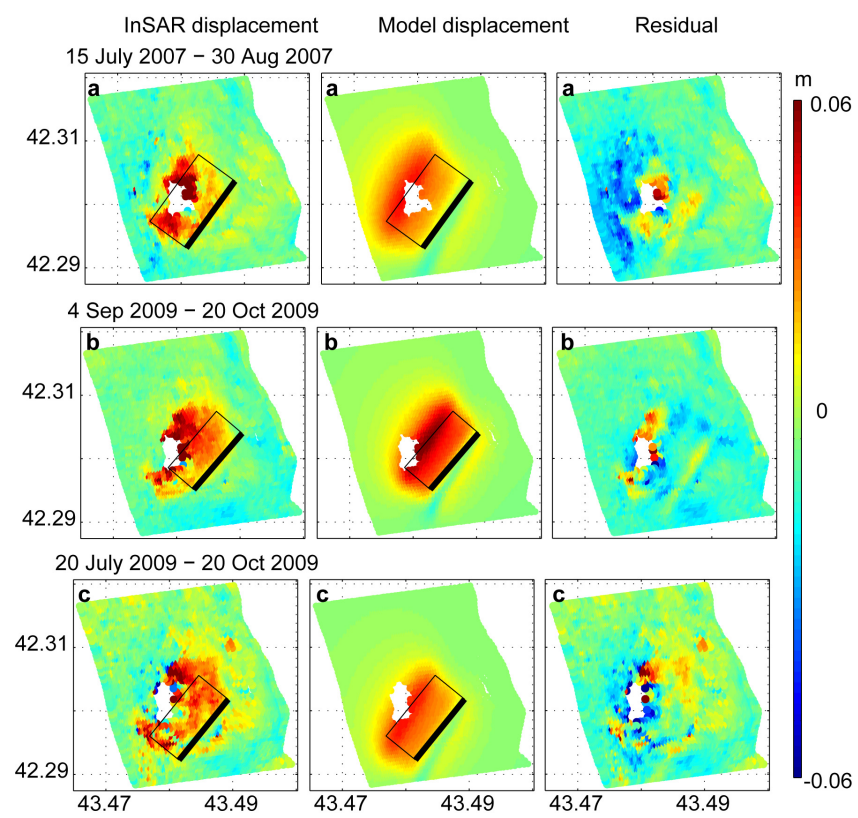

Fig. 8. Observed quantities (left), modelled quantities (middle) and the residual (right). The mining activity was not accounted for in the modelling. The parameters of the model are given in Table 1.

trees or their remnants inside the ponds, which supports the idea that the ponds have appeared recently.

We identified visible scarps for this region from the aerial photograph and field observations (Fig. 7). The major areas of debris are on the eastern slope of the landslide. Over the course of our field season, the debris flow tracks, debris fan deposits and scars evolved. Newly formed cracks hidden by vegetation were found during field surveying.

The area affected by landslide processes was calculated in GIS using a polygon created based on InSAR, aerial photography and field observations (Fig. 7). We found that the area of the kidney-shaped landslide identified by its morphology is approximately $2.9 \mathrm{~km}^{2}$, the perimeter of total area affected by the landslide is approximately $7.48 \mathrm{~km}$, and the area having a displacement signal from InSAR is approximately $0.9 \mathrm{~km}^{2}$.

\subsection{Modelling results}

We inverted the three best interferograms with temporal baselines of 46 or 92 days. Figure 8 shows the observed displacements from InSAR data, model simulations of the same geometry and residuals that show the difference between those two displacement fields. In all these data sets, the optimum décollement plane is sub-horizontal and dips slightly to the northwest. The residuals are generally less than $5 \mathrm{~cm}$, which means that the signal was simulated very well and the residuals approach the noise level. The highest residual is in the deposition zone of the landslide. Table 1 shows the output parameters for the model initiated with different values of input parameters. We detected a slight variation in the location and geometry of the sliding plane. For example, the dip ranges between $-7^{\circ}$ and $-9^{\circ}$ westward, the strike ranges between $35^{\circ}$ and $40^{\circ}$ northeast-southwest, the dip slip ranges between -12 and $-0.17 \mathrm{~m}$ to the northwest and the depth ranges from 120 to $190 \mathrm{~m}$ below the surface. As these inversions provide an indirect view on the décollement plane, we can now elaborate on the landslide volume.

\subsection{Landslide volume}

Using the ellipsoid segment concept, we calculated the geometrically predicted volume based on the surface affected and the location of the décollement plane. We present displacement on the surface as an ellipse with semi-major axes $\mathrm{A}$ and $\mathrm{B}$, which have values of 1 and $0.3 \mathrm{~km}$, respectively (Fig. 3). The axis $A$ is found from modelling as the length parameter (average $0.65 \mathrm{~km}$ ) and $h$ is the modelled depth of the detachment plane (average $0.12 \mathrm{~km}$ ). Based on these parameters and using Eq. (2), we estimated the volume of the Itskisi landslide to be $0.09 \mathrm{~km}^{3}$. We did not include dip in our volume estimation because the slope of the target area is approximately $10^{\circ}$, which is similar to the dip angle of the décollement as obtained from inverse modelling.

Following the empirical Eq. (3) and using the affected landslide area as determined from InSAR, we obtain a landslide volume of approximately $0.046 \mathrm{~km}^{3}$, which is half the volume estimated above. Several reasons may explain this difference. Firstly, we do not take the slope of the planes that are truncated ellipsoids into account. Secondly, the exponent 1.3 is applicable for both shallow soil-based and for deep bedrock landslides. We choose this coefficient only because we have no accurate data about the location of the bedrock. In both case, the models were simplified by the half space assumption. In other words, topography and material heterogeneity were not considered. 


\section{Discussion}

In this work, only a limited satellite radar data set was available. In Georgia this may result from a combination of political sensitivities, lack of previous scientific interest, and acquisition conflicts with other study areas.

The remaining data, however, allowed us to obtain new insights into a specific landslide case in Georgia. Eight reliable interferograms spanning over 3 years were produced to map the extent and amount of movement on the ground. Out of these, three interferograms have a noise level that makes them difficult to interprete, whereby up to $50 \%$ of the expected signal is attributed to noise. The remaining five interferograms, however, were of a high and consistent quality.

In this work we speculate about the relationship between landslide acceleration and extrinsic processes. We note that although an earthquake occurred during the observation period, at a time coinciding with the largest landslide displacements in the InSAR data set, additional and complementary data at the landslide site would be needed to make a stronger case for a direct relationship between these events. As long as in-site observations are not made of the Itskisi landslide or similar landslides, a clear understanding of external triggers remains elusive. The same limitation also concerns rainfall data. No accurate weather data was available to us, which is why we herein used weather models instead of in-site rain gauge observation.

The relationship of a landslide area to anthropogenic activities, here meaning mining is a critical issue. Because the Itskisi landslide has destroyed the Itskisi village and is threatening others, liability issues restrict a great deal of scientific communication between ourselves and mine operators. In addition, our own survey showed that not only one mining company but at least 17 are involved in extracting sands from the landslide toe region, which makes a control on extraction rates and volume even more difficult. Here we relied more on satellite imagery (Landsat), which clearly show the vast spread of the area of effected by mining.

We use both InSAR and optical data for the detection and kinematic analysis of a landslide in Georgia. The landslide is $0.9 \mathrm{~km}^{2}$ in area, subject to a motion of up to $6 \mathrm{~cm}$ within 46 days and affects a populated region and a major mining site. Although we use radar data from a single direction (ascending satellite pass) only, the combination of InSAR displacement maps, aerial photography analysis and modelling provides information about the landslide dynamics. One of the important problems that may be encountered in the processing of radar images is the loss of coherence due to spatial or temporal factors. For this reason, we excluded some interferograms from our analysis and modelling. In the following section, we discuss the effects of extrinsic processes, such as those related to rainfall, earthquake and mining activity, on landslide dynamics.

\subsection{Impacts}

The landslide may affect surrounding infrastructure, population and river flow. Landslide can dam river (Fig. 7), which may induce major hydrological hazards such as floods or the loss of drinking water resources. Landslide also affects erosion and can cause short-term losses of topsoil and vegetation. Landslide damming has both short- and long-term effects (Schuster and Highland, 2003). The Itskisi landslide directly affected four villages: Itskisi, Makhatauri, Savane and Irtavaza (Fig. 10). The village of Itskisi was located directly on the landslide and moved downslope. Houses there were damaged, and most of the population left the village. The villages Savane and Makhatauri are separated by a river at the foot of landslide. In the scenario of landslide occurrence, the landslide may block a river and reach the village Savane, which is approximately $300 \mathrm{~m}$ away from the landslide area. The village Itavaza is located on the opposite slope of the landslide.

Understanding this type of landslide is therefore particularly important because eyewitnesses have reported increase in landslide hazards and risk over the past few decades.

\subsection{Factors triggering landslides}

A displacement signal is detected in each interferogram shown in Figure 4 and is particularly strong in interferograms with short temporal baselines. Because variation in the displacement rates affects only the kidney-shaped landslide area and not the stable surroundings, we conjecture that this variation is not an artefact. The normalised velocity value suggests highly variable slip rates. The changes in the velocity may be due to variations in groundwater, which are a function of rainfall intensity or seasonal water variations such as snowmelt.

We select the average velocity at four different places on the landslide (Fig. 4a-h) to investigate the relationship between changes in velocity and precipitation. We compare these velocities to average monthly precipitation data (Fig. 9 black curve), which are based on the atmospheric general circulation model ECHAM5 (http://www.mpimet.mpg.de). The spatial resolution is roughly equivalent to 2.8 degrees in both directions, latitude and longitude (Roeckner et al., 2003). The period from June 2007 to January 2010 has a maximum precipitation value of $150 \mathrm{~mm}$. The interferograms from 17 October 2008 to 4 March 2009, 2 December 2008 to 4 March 2009 and 20 October 2009 to 20 January 2010 (Fig. 4) cover periods with monthly precipitation below $150 \mathrm{~mm}$, while all other interferograms cover intervals with monthly precipitation less than $100 \mathrm{~mm}$. The velocity in the interferogram from 2 December 2008 to 4 March 2009 is slightly higher $\left(0.01 \mathrm{~cm} \mathrm{day}^{-1}\right)$ than in the interferogram from 4 March 2009 to 20 July 2009. However, we observe that the interferograms that display highest landslide displacements do not concur with episodes of high monthly 


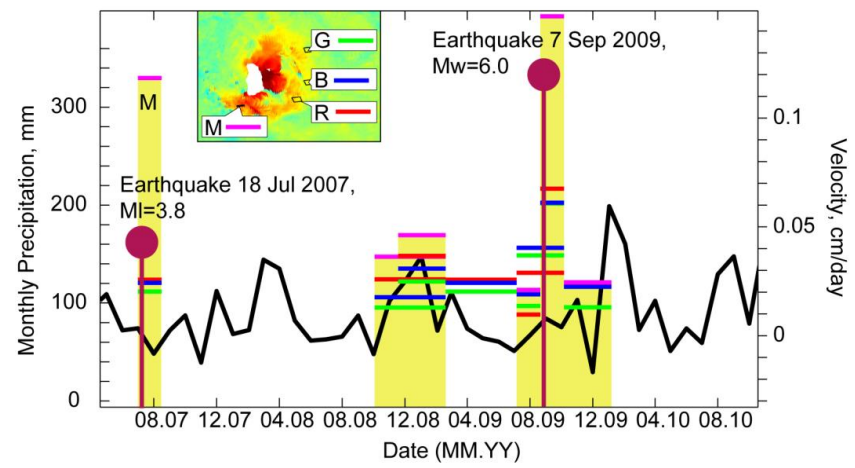

Fig. 9. Distribution of precipitation (black curve, left scale) based on ECHAM5. The coloured lines (green, blue, red) and bar graphs (magenta) show velocities (right scale) within the area identified by letters "R", "G", "B", "M" in Fig. 4a.

average precipitation (Fig. 9). These interferograms cover the time from 20 July 2009 to 20 October 2009 and 15 July 2007 to 30 August 2007. Thus, the apparent acceleration of the landslide in September-October 2009 cannot be explained by rainfall.

Inspection of the global earthquake catalogue (CMT) shows that a magnitude $\mathrm{Mw}=6.0$ earthquake on 7 September 2009 occurred at $10 \mathrm{~km}$ depth and a distance of only approximately $30 \mathrm{~km}$ from the landslide. On 18 July 2007, another earthquake occurred, this one with magnitude $\mathrm{Ml}=3.8$ at $15 \mathrm{~km}$ depth (http://seismo.iliauni.edu.ge/) at a distance of $12 \mathrm{~km}$. The observed increase of the displacement rates at these times suggests that these earthquakes may have had a triggering influence. Such a triggering influence is in agreement with work by Jibson et al. (1994), where numerous landslides were triggered following an earthquake at a distance of approximately $30 \mathrm{~km}$.

These discussions are relevant given the ongoing mining activity during the period of this study. There is $68.07 \mathrm{Ha}$ of mining area covered by 17 mining companies (source: www.gwp.org, licenses issued for the use of mineral resources in Georgia), as shown in Fig. 2 (bright areas). These images do not allow clear analysis of the landslide, but they do show the development of mining activity (Fig. 2, bright areas). Quartz sand extraction began in 1968 and accelerated greatly in 2007 , reaching rates that continue today. This may explain why the points closest to the active mines show the highest velocities in 2007 (Fig. 9, margin line, year 2007).

We conclude that the landslide may have been triggered by rainfall, earthquakes and the man-made removal of the toe. Unfortunately, due to the lack of good topographic data, ground data and field information at that time, no clear relation between the earthquakes and the triggering of the landslide movements could be found.

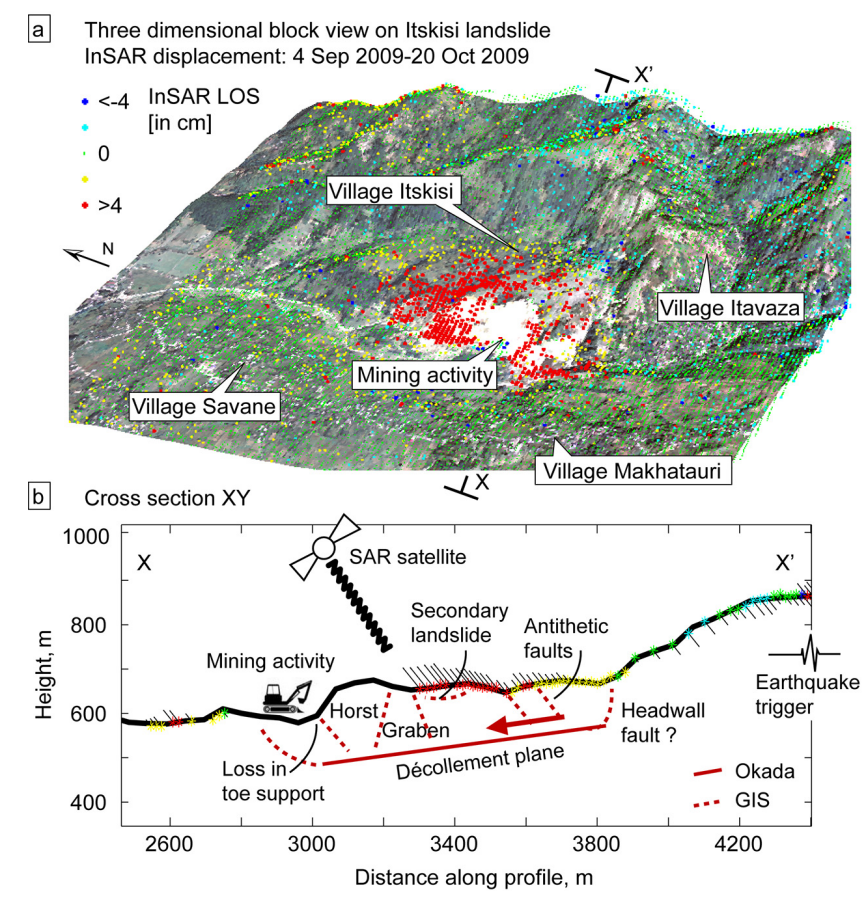

Fig. 10. (a) Three-dimensional GIS visualisation showing InSARmeasured displacements in cm (4 April 2009-20 October 2009) on a digital elevation surface (ASTER, resolution $30 \mathrm{~m}$ ) combined with an aerial photograph. The area is $3.5 \mathrm{~km}$ east-west by $4.8 \mathrm{~km}$ northsouth in size. The colour scale bar indicates displacement. Four villages were affected by the landslide. (b) The profile along the region of interest runs west-east along the $X-X^{\prime}$ transect shown in (a). The colour scale for the profile points is the same as for the 3-D visualisation above. The vectors are directed to the line-of-sight. The length of the vector indicates the magnitude of the displacement, which was artificially increased by a factor of 100 for better visibility. The slip plane for the Itskisi landslide is estimated based on results from remote sensing, field observations and modelling. Our model favours the landslide to be complex, with both a translational part (Okada model) and rotational elements (dashed red curves).

\subsection{Conceptual model}

Our structural mapping and analysis of InSAR data suggest that several smaller sliding blocks combine to form the larger landslide complex. We applied a model to study the internal geometry of the landslide.

Inspired by the research of Fleming and Johnson (1989), Muller and Martel (2000) and Martel (2004), we use a dislocation model to evaluate the depth of the sliding plane. The hypothesis is that the structures of large landslides are similar to tectonic faults. For instance, the seismic and geodetic observations confirmed analogous behaviour of landslide detachment planes and tectonic faults (Gomberg and Bodin, 1995). Moreover, the geometry of these two elements may also be related, as was found between adjacent ridges parallel to the San Andreas Fault in the Carizzo Plains of California and the trend of the slide-bounding strike-slip fault on 
the Slumgullion landslide in Colorado (Gomberg and Bodin, 1995). In our model, we had to ignore parameters that may play important roles in the development of the landslide process. We did not consider possible material heterogeneity, nor did we take into account topography or the distributions of possible driving forces and gravitation. Our model also does not show the evolution of a landslide and secondary slides and has difficulty predicting the true shape of the sliding plane. However, in the first approximation, the model selects the potential sliding plane most susceptible to failure from an infinite number of potential surfaces. In addition, translational slides can be connected to upslope and downslope rotational slides (Fig. 10). The lengths of the displacement vectors remain the same at certain areas (Fig. 10, profile), and the distribution of the displacement vectors is a function of the slip-surface sliding plane (Casson et al., 2005). The equal displacement vectors in the centre zone of the landslide indicate a uniform translational landslide there (Casson et al., 2005). However, the lengths of the displacement vectors increase from east to west, which implies the presence of rotational landslide elements in the upper zone (Fig. 10, profile).

The complete picture of the landslide therefore consists of a planar (translational) fault at depth that curved toward the toe and headwall to form a combined rotational-translational landslide body. Secondary landslides developed and migrated, piggybacking on each other. Antithetic faults and horst and graben structures developed. The grabens formed ponds and destroyed the Itskisi village, whereas the horst structures are currently exploited by mining activity. A local girdle of subsidence surrounding the mine highlights the effects of the loss of toe support. Landslides may be triggered by mining intensification (as in 2007) or earthquakes (as in 2009). A direct link to rainfall was not found, though we note that the rainfall database was poor.

Previous studies show the efficiency of combining different remote sensing images for monitoring and characterising landslide processes (Strozzi et al., 2005; Casson et al., 2005). Using both radar and optical satellite images allows us to trace the behaviour of landslides in space and time and to evaluate an area affected by possible landslides. A conceptual model was developed based on observational data from remote sensing (Casson et al., 2005). The aim of the conceptual model is the evaluation of the volume of possible landslides for the hazard mass movement.

\section{Conclusions and perspective}

Landslides in the area of the Caucasus Mountains are not well monitored due to the high costs and difficult logistics of doing so. As we demonstrate, the combination of InSAR data, aerial photography analysis, Landsat imagery and other information allows us to identify and monitor a landslide in the centre part of Georgia. The displacement rate of the land- slide is from $10 \mathrm{~cm} \mathrm{year}^{-1}$ to $30 \mathrm{~cm}_{\text {year }}{ }^{-1}$, covering an area of approximately $0.9 \mathrm{~km}^{2}$. Our data suggest that the landslide movement is not stable, occasionally displaying a significant acceleration. These episodes of high landslide mobility may be associated with potential external triggering mechanisms, such as rainfall, man-made activity or a tectonic earthquake.

We characterise the landslide movement and determine displacement velocities within the landslide body. By combining this work with modelling, we are able to more precisely explore the dimensions and detachment plane geometry and further illuminate potential hazards and environmental interactions. The maximum depth of the landslide detachment plane ranges from 0.12 to $0.19 \mathrm{~km}$.

Field observations show good correlation of surface fractures and the displacements obtained from InSAR data (Figs. 5 and 6). We identify a number of factors that may trigger landslides. Mining caused a loss of mass in the toe. The intensification of mining exploration locally increased the landslide velocity. In addition, the most dramatic velocity increase was found in association with a $\mathrm{Mw}=6.0$ earthquake located $30 \mathrm{~km}$ from the landslide.

This landslide poses threats to human lives and structures that support transportation and natural resource management in four villages. The landslide or its part may be activated given the proximity $(\sim 30 \mathrm{~km})$ of a possible focus of a strong earthquake (Keefer 1994; Wasowski, 2002).

This finding has important implications for hazard assessment because the location and type of landslides in Georgia apparently vary in time. The mining industry, which provides and improves infrastructure and prosperity in the region, also may contribute to triggering landslides.

Over the past 30 years, the use of remote sensing techniques in the geosciences has increased dramatically. The number of satellites with various temporal and spatial resolutions, bands and broad coverage has also increased. In this regard, there is greater opportunity to explore an event with various data sets. The probability of data being available for unexpected geological disasters is also higher. This remote sensing development plays a major role for creating a data archive for Georgia, where high hazards exist but only small numbers of observational tools are used.

The results of this study demonstrate that complex remote sensing techniques have the potential to become good tools for early warning of landslide disasters. Satellite data allow monitoring landslides in space and time. The displacement distribution obtained from InSAR data can be used in a model to characterise the geometry and spatial evolution of the landslide slip surface. Its temporal evolution can also be investigated with remote sensing data.

Our work suggests the landslide to have a decade long history, which is developing. From Landsat imagery we see that the man-made activity has significantly increased. Our own survey and questioning of residents further support the fact that the mining activity has strongly increased in the past 8 years. One may speculate that the effect of man-made activity 
on landsliding may even augment more risk as unloading in the toe region continues. Moreover, as the landslide is hence further developing, also interacting processes, such as earthquake or rainfall triggering may alter with time. Therefore, close observation and further work with a more regular data acquisition are needed, allowing detection of displacement rate changes at higher detail. Also, monitoring of mining activity may also help to clarify the impact that man-made actions have on natural hazards. In this view, the Itskisi landslide may provide an excellent laboratory, where such interacting and cascading processes might be well studied.

Acknowledgements. The authors would like to thank the DAAD (German Academic Exchange Service) for financially supporting the $\mathrm{PhD}$ research of Elena Nikolaeva, the Institute of Earth Sciences at Ilia State University in Tbilisi (Georgia) for organisation of fieldwork and providing aerial photographs, Henriette Sudhaus and Hannes Bathke for their valuable advice during the processing of radar data and Michele Pantaleo for geology discussions. Financial support also came from the HGF Alliance EDA.

The service charges for this open access publication

have been covered by a Research Centre of the

Helmholtz Association.

Edited by: P. Tarolli

Reviewed by: two anonymous referees

\section{References}

Canuti, P., Casagli, N., Catani, F., Falorni, G., and Farina, P.: Integration of Remote Sensing Techniques in Different Stages of Landslide Response, Prog. Landslide Sci., 251-260, 2007.

Cardenal, J., Mata, E., Delgado, J., Hernandez, M. A., and Gonzalez, A.: Close range digital photogrammetry techniques applied to landslides monitoring, Int. Arch. Photogramm. Remote Sens. Spat. Inf. Sci., XXXVII, 235-240, 2001.

Casson, B., Delacourt, C., and Allemand, P.: Contribution of multitemporal remote sensing images to characterize landslide slip surface? Application to the La Clapière landslide (France), Nat. Hazards. Earth Syst. Sci., 5, 425-437, doi:10.5194/nhess-5-4252005, 2005.

Chen, C., Zhang, J., and Lu, L.: Identification of Layover and Shadow Regions in InSAR Image, 2011 Int. Symp. Image Data Fusion, IEEE, 1-4, 2011.

Chen, C. W. and Zebker, H. A.: Phase unwrapping for large SAR interferograms: Statistical segmentation and generalized network models, IEEE Trans. Geosci. Remote Sens., 40, 1709-1719, 2002.

Chudnovsky, A. and Ben-Dor, E.: Application of visible, nearinfrared, and short-wave infrared (400-2500 nm) reflectance spectroscopy in quantitatively assessing settled dust in the indoor environment. Case study in dwellings and office environments, Sci. Total Environ., 393, 198-213, 2008.

Colesanti, C., Ferretti, A., Novali, F., Prati, C., and Rocca, F.: SAR monitoring of progressive and seasonal ground deformation us- ing the permanent scatterers technique, IEEE Trans Geosci. Remote Sens., 41, 1685-1701, 2003a.

Colesanti, C., Ferretti, A., Prati, C., and Rocca, F.: Monitoring landslides and tectonic motions with the Permanent Scatterers Technique, Eng. Geol., 68, 3-14, 2003 b.

Colesanti, C. and Wasowski, J.: Investigating landslides with spaceborne Synthetic Aperture Radar (SAR) interferometry, Eng. Geol., 88, 173-199, doi:10.1016/j.enggeo.2006.09.013, 2006.

Cruden, D. M.: The geometry of slip surfaces beneath landslides: predictions from surface measurements: Discussion. Can. Geotech. J., 23, p. 94, doi:10.1139/t86-012, 1986.

Cruden, D. M. and Varnes, D. J.: Landslide types and processes, in: Landslides - Investigation and Mitigation, edited by: Turner, A. T., Schuster, R. L., Transp. Res. Board, Spec. Rep., 247, 36-75, doi:10.1007/BF02590167, 1996.

Delacourt, C., Allemand, P., Berthier, E., Raucoules, D., Casson, B., Grandjean, P., Pambrun, C., and Varel, E.: Remote-sensing techniques for analysing landslide kinematics: a review, Bull. Soc. Geol. Fr., 178, 89-100, doi:10.2113/gssgfbull.178.2.89, 2007.

Edilashvili, V. Y. Y., Lekvinadze, R. D., and Gogiberidze, V. V.: Effect of tectonics on manganese accumulation in Georgia, Int. Geol. Rev., 16, 37-41, doi:10.1080/00206817409471856, 1974.

Fleming, R. W. and Johnson, A. M.: Structures associated with strike-slip faults that boundlandslide elements, Eng. Geol., 27, 39-114, doi:10.1016/0013-7952(89)90031-8, 1989.

Fruneau, B., Achache, J., and Delacourt, C.: Observation and modelling of the Saint-Étienne-de-Tinée landslide using SAR interferometry, Tectonophysics, 265, 181-190, doi:10.1016/S00401951(96)00047-9, 1996.

Gamkrelidze, I. and Shengelia, D.: Pre-Alpine Geodynamics of the caucasus, Suprasubduction Regional Metamorphism and Granitoid Magmatism, Bull. Georg. Natl. Acad. Sci., 175, 57-65, 2007.

García-Davalillo, J. C., Herrera, G., Notti, D., Strozzi, T., and Álvarez-Fernández, I.: DInSAR analysis of ALOS PALSAR images for the assessment of very slow landslides: the Tena Valley case study, Landslides, doi:10.1007/s10346-012-0379-8, 2013.

Goldstein, R. M. M. and Werner, C. L. L.: Radar interferogram filtering for geophysical applications, Geophys. Res. Lett., 25, 4035-4038, 1998.

Gomberg, J. and Bodin, P.: Landslide faults and tectonic faults, analogs?: The Slumgullion earthflow, Colorado. Geology, 23, 41-44, doi:10.1130/00917613(1995)023<0041:LFATFA>2.3.CO;2, 1995.

Gracheva, R. and Golyeva, A.: Landslides in mountain regions: hazards, resources and information, in: Geophys. Hazards, Int. Year Planet Earth, edited by: Beer, T., Springer Netherlands, Dordrecht, 249-260, 2010.

Guzzetti, F., Manunta, M., Ardizzone, F., Pepe, A., Cardinali, M., Zeni, G., Reichenbach, P., and Lanari, R.: Analysis of Ground Deformation Detected Using the SBAS-DInSAR Technique in Umbria, Central Italy, Pure Appl. Geophys., 166, 1425-1459, 2009.

Guzzetti, F., Mondini, A. C., Cardinali, M., Pepe, A., Cardinali, M., Zeni, G., Reichenbach, P., and Lanari, R.: Landslide inventory maps: New tools for an old problem, Earth-Science Rev., 112, 42-66, 2012.

Hanssen, R. F.: Radar Interferometry: Data Interpretation and Error Analysis, 328 pp., 2001. 
Highland, L. M. and Bobrowsky, P.: The Landslide Handbook - A Guide to Understanding Landslides, Landslides, 129 pp., 2008.

Hilley, G. E., Bürgmann, R., Ferretti, A., Novali, F., and Rocca, F.: Dynamics of slow-moving landslides from permanent scatterer analysis, Science, 304, 1952-5, 2004.

Hovius, N., Stark, C. P., and Allen, P. A.: Sediment flux from a mountain belt derived by landslide mapping, Geology, 25, 231234, 1997.

Jaboyedoff, M., Oppikofer. T., Abellán, A., Derron, M.-H., Loye, A., Metzger, R., and Pedrazzini, A.: Use of LIDAR in landslide investigations: a review, Nat. Hazards., 61, 5-28, 2010.

Jibson, R. W., Randall, W., and Prentice, C. S.: Ground Failure Produced by the 29 April 1991 Racha Earthquake in Soviet Georgia, US Geol. Surv., 10, Open-File Report 91-392, ii, 5 leaves, 1991.

Jibson, R. W., Prentice, C. S., Borissoff, B. A., Rogozhin, E. A., and Langer, C. J.: Some observations of landslides triggered by the 29 April 1991 Racha earthquake, Republic of Georgia, Bull. Seismol. Soc. Am., 84, 963-973, 1994.

Kampes, B. and Usai, S.: Doris: The Delft object-oriented radar interferometric software, 2nd Int Symp Oper Remote Sens Enschede Netherlands, 1-4, doi:10.1.1.46.1689, 1999.

Keefer, D. K.: The importance of earthquake-induced landslides to long-term slope erosion and slope-failure hazards in seismically active regions, Geomorphology, 10, 265-284, 1994.

Larsen, I. J., Montgomery, D. R., and Korup, O.: Landslide erosion controlled by hillslope material, Nat. Geosci., 3, 247-251, 2010.

Leonov, M. G.: Fractures in the Dzirula massif (Georgia), Int. Geol. Rev., 18, 1019-1024, 1976.

Malamud, B. D., Turcotte, D. L., Guzzetti, F., and Reichenbach, P.: Landslide inventories and their statistical properties, Earth Surf Proc. Landforms, 29, 687-711, 2004.

Martel, S.: Mechanics of landslide initiation as a shear fracture phenomenon, Mar. Geol., 203, 319-339, 2004.

Martha, T. R., Kerle, N., Jetten, V., van Westen, C. J., and Kumar, K. V.: Characterising spectral, spatial and morphometric properties of landslides for semi-automatic detection using object-oriented methods, Geomorphology, 116, 24-36, 2010.

Muller, J. R. and Martel, S. J.: Numerical Models of Translational Landslide Rupture Surface Growth, Pure Appl. Geophys., 157, 1009-1038, 2000.

Nadim, F., Kjekstad, O., Peduzzi, P., Herold, C., and Jaedicke, C.: Global landslide and avalanche hotspots, Landslides, 3, 159-173, 2006.

Nichol, J. and Wong, M. S.: Satellite remote sensing for detailed landslide inventories using change detection and image fusion, Int. J. Remote Sens., 26, 1913-1926, 2005.

Okada, Y.: Surface deformation due to shear and tensile faults in a half-space, Int. J. Rock Mech. Min. Sci. Geomech. Abstr., 75, 1135-1154, 1985.

Ouimet, W. B.: Landslides associated with the May 12, 2008 Wenchuan earthquake: Implications for the erosion and tectonic evolution of the Longmen Shan, Tectonophysics, 491, 244-252, 2010.

Perski, Z., Hanssen, R., Wojcik, A., and Wojciechowski, T.: InSAR analyses of terrain deformation near the Wieliczka Salt Mine, Poland, Eng. Geol., 106, 58-67, 2009.
Petley, D. N., Bulmer, M. H., and Murphy, W.: Patterns of movement in rotational and translational landslides, Geology, 30, 719 722, 2002.

Petley, D. N., Mantovani, F., Bulmer, M. H., and Zannoni, A.: The use of surface monitoring data for the interpretation of landslide movement patterns, Geomorphology, 66, 133-147, 2005.

Principe, J. C., De Vries, B., De Oliveira, P. G., De Vries, B., and De Oliveira, P. G.: The gamma-filter-a new class of adaptive IIR filters with restricted feedback, IEEE Trans Sig. Proc., 41, 3378 3393, 2004.

Qi, S., Xu, Q., Lan, H., De Vries, B., and De Oliveira, P. G.: Spatial distribution analysis of landslides triggered by 2008.5 .12 Wenchuan Earthquake, China. Eng. Geol., 116, 95-108, 2010.

Riedel, B. and Walther, A.: InSAR processing for the recognition of landslides, Adv. Geosci., 14, 189-194, 2008, http://www.adv-geosci.net/14/189/2008/.

Roeckner, E., Bäuml, G., Bonaventura, L., Brokopf, R., Kornblueh, M., Giorgetta, M., Hagemann, S., Kirchner, I., Tompkins, E., Manzini, A., Rhodin, U., Schlese, U., and Schulzweida, A.: The atmospheric general circulation model ECHAM5 - Part I: Model description, 349 pp., 2003.

Sandwell, D. T., Myer, D., Mellors, R., Shimada, M., Brooks, B., and Foster, J.: Accuracy and Resolution of ALOS Interferometry: Vector Deformation Maps of the Father's Day Intrusion at Kilauea, IEEE Trans. Geosci. Remote Sens., 46, 3524-3534, 2008.

Schulz, W. H.: Landslides mapped using LIDAR imagery, North, 4 11 pp., 2004.

Schuster, R. L. and Highland, L. M.: Impact of landslides and innovative landslide-mitigation measures on the natural environment, Geol. Hazards Team, US Geol., 2003.

Shirzaei, M. and Walter, T. R.: Randomly iterated search and statistical competency as powerful inversion tools for deformation source modeling: Application to volcano interferometric synthetic aperture radar data, J. Geophys. Res., 114, 1-16, 2009.

Shirzaei, M. and Walter, T. R.: Estimating the Effect of Satellite Orbital Error Using Wavelet-Based Robust Regression Applied to InSAR Deformation Data, IEEE Trans. Geosci. Remote Sens., 49, 4600-4605, 2011.

Strozzi, T., Farina, P., Corsini, A., Ambrosi, C., Thüring, M., Zilger, J., Wiesmann, A., Wegmüller, U., and Werner, C.: Survey and monitoring of landslide displacements by means of L-band satellite SAR interferometry, Landslides, 2, 193-201, 2005.

Strozzi, T., Ambrosi, C., and Raetzo, H.: Interpretation of Aerial Photographs and Satellite SAR Interferometry for the Inventory of Landslides, Remote Sens., 5, 2554-2570, 2013.

Tofani, V., Segoni, S., Agostini, A., Catani, F., and Casagli, N.: Technical Note: Use of remote sensing for landslide studies in Europe, Nat. Hazards. Earth Syst. Sci., 13, 299-309, doi:10.5194/nhess-13-299-2013, 2013.

Van Westen, C. J., Straatsma, M. W., Turdukulov, U. D., Feringa, W. F., Sijmons, K., Bakhtadze, K., Janelidze, T., and Kheladze, N.: Atlas of Natural Hazards and Risk in Georgia, CENN Caucasus Environmental NGO Network, 2012.

Wei, M. and Sandwell, D. T.: Decorrelation of L-Band and C-Band Interferometry Over Vegetated Areas in California, IEEE Trans Geosci. Remote Sens., 48, 2942-2952, 2010. 